\title{
Runella limosa sp. nov., isolated from activated sludge
}

\author{
Seung Hyun Ryu, ${ }^{1}$ Thi Thu Hien Nguyen, ${ }^{1}$ Woojun Park, ${ }^{2}$ Chang-Jin Kim ${ }^{3}$ \\ and Che Ok Jeon ${ }^{1}$ \\ ${ }^{1}$ Division of Applied Life Science, EB-NCRC, PMBBRC, Gyeongsang National University, Jinju \\ 660-701, Republic of Korea \\ ${ }^{2}$ Division of Environmental Science and Ecological Engineering, Korea University, Seoul 136- \\ 701, Republic of Korea \\ ${ }^{3}$ Korea Research Institute of Bioscience and Biotechnology, 52 Oeundong, Yusong, Daejeon \\ 305-333, Republic of Korea
}

Correspondence

Che Ok Jeon

cojeon@gnu.ac.kr

\begin{abstract}
A Gram-negative bacterium, designated strain $\mathrm{EMB} 111^{\top}$, was isolated from activated sludge performing enhanced biological phosphorus removal in a sequencing batch reactor. Cells were long and rod-shaped. The isolate was strictly aerobic and non-motile. The strain grew optimally at $25-30{ }^{\circ} \mathrm{C}$ and $\mathrm{pH} 7 \cdot 5-8 \cdot 0$. The predominant fatty acids of strain $\mathrm{EMB} 111^{\top}$ were iso- $\mathrm{C}_{15: 0}$, $\mathrm{C}_{16: 1} \omega 5 c$, iso- $\mathrm{C}_{17: 0} 3-\mathrm{OH}$, iso- $\mathrm{C}_{15: 0} 3-\mathrm{OH}, \mathrm{C}_{16: 0} 3-\mathrm{OH}, \mathrm{C}_{16: 0}$ and summed feature 3 $\left(\mathrm{C}_{16: 1} \omega 7 \mathrm{c}\right.$ and/or iso- $\left.\mathrm{C}_{15: 0} 2-\mathrm{OH}\right)$. The strain contained a large amount of phosphatidylglycerol and small amounts of two unknown phospholipids (PL1, PL2) as the polar lipids. The major isoprenoid quinone was menaquinone- 7 . The $\mathrm{G}+\mathrm{C}$ content of the genomic DNA was $42 \cdot 7 \mathrm{~mol} \%$. Phylogenetic analysis showed that strain $\mathrm{EMB} 111^{\top}$ formed a phyletic cluster with members of the genus Runella within the family Flexibacteraceae and was most closely related to Runella slithyformis ATCC $29530^{\top}$ with a $16 \mathrm{~S}$ rRNA gene sequence similarity of $94 \cdot 8 \%$. On the basis of chemotaxonomic data and molecular properties, strain EMB $111^{\top}$ represents a novel species within the genus Runella, for which the name Runella limosa sp. nov. is proposed. The type strain is EMB $111^{\top}\left(=\right.$ KCTC $\left.12615^{\top}=\operatorname{DSM} 17973^{\top}\right)$.
\end{abstract}

The genus Runella, a member of the family Flexibacteraceae, phylum Bacteroidetes (formerly Flexibacter-BacteroidesFlavobacterium), was first erected by Larkin \& Williams (1978). At the time of writing, the genus comprised two recognized species, Runella slithyformis and Runella zeae (Larkin \& Williams, 1978; Chelius et al., 2002). R. slithyformis has an aquatic lifestyle; by contrast, $R$. zeae was isolated from the stems of surface-sterilized maize (Zea mays). This suggests that members of the genus Runella can be isolated from diverse environmental habitats. In this study, we describe a novel species of the genus Runella isolated from an activated sludge process performing enhanced biological phosphorus removal.

Strain EMB111 ${ }^{\mathrm{T}}$ was isolated from activated sludge performing enhanced biological phosphorus removal in a laboratory-scale sequencing batch reactor. Sodium acetate

The GenBank/EMBL/DDBJ accession number for the 16S rRNA gene sequence of strain $\mathrm{EMB} 111^{\top}$ is DO372985.

A transmission electron micrograph showing the general morphology of negatively stained cells of strain EMB $111^{\top}$ is available as a supplementary figure in IJSEM Online. was supplied as the sole carbon source, and the operation of the reactor was as described by Jeon et al. (2003). A sludge sample was serially diluted in $1 \%(\mathrm{w} / \mathrm{v})$ saline solution, spread on R2A agar (Difco) and incubated at $20{ }^{\circ} \mathrm{C}$ for 5 days. Subcultivation was on R2A agar at $25^{\circ} \mathrm{C}$ for 3 days. Gram staining was performed using the bioMérieux Gram stain kit according to the manufacturer's instructions. Cell morphology and motility were studied by using phasecontrast microscopy and transmission electron microscopy (JEM-1010; JEOL) as described by Jeon et al. (2005). Physiological characteristics of strain EMB111 ${ }^{\mathrm{T}}$ were examined by growing the isolate on R2A medium at different temperatures and $\mathrm{pH}$ values. R2A media with different $\mathrm{pH}$ values were prepared as described by Gomori (1955). Oxidase activity was tested by oxidation of $1 \%(\mathrm{w} / \mathrm{v})$ tetramethyl- $p$-phenylenediamine (Merck) and catalase activity was evaluated by production of oxygen bubbles in $3 \%(\mathrm{v} / \mathrm{v})$ aqueous hydrogen peroxide solution. Hydrolysis of tyrosine, Tweens 20 and 80, aesculin, casein, starch, gelatin and urea was assessed on R2A agar after 5 days incubation according to the methods described by Lanyi (1987) and Gerhardt et al. (1994). Nitrate reduction was performed according to the method of Lanyi (1987) and 
acid production from carbohydrates was tested as described by Leifson (1963). Additional enzyme activities and biochemical characteristics were determined by using the API ZYM and API 20E kits as recommended by the manufacturer (bioMérieux). Strain EMB111 ${ }^{\mathrm{T}}$ on R2A agar formed slightly raised, circular, salmon-pink colonies when grown at $25^{\circ} \mathrm{C}$ for 3 days. Growth was observed at temperatures between 15 and $40^{\circ} \mathrm{C}$, with an optimum growth temperature range of $25-30^{\circ} \mathrm{C}$. The strain grew at $\mathrm{pH} 6 \cdot 0-9 \cdot 0$, with an optimum $\mathrm{pH}$ range of $7 \cdot 5-8 \cdot 0$. Cells of the isolate were non-motile, long rods $(0 \cdot 7-0 \cdot 9 \mu \mathrm{m}$ wide and $4 \cdot 0-10 \cdot 0 \mu \mathrm{m}$ long) that lacked flagella (see Supplementary Fig. S1 in IJSEM Online). Cells of strain EMB111 ${ }^{\mathrm{T}}$ were Gramnegative, oxidase-negative and catalase-positive and did not reduce nitrate to nitrite. The isolate was negative for production of indole, $\mathrm{H}_{2} \mathrm{~S}$ and acetoin and for utilization of citrate (API 20E). Growth was not observed under anaerobic conditions over a 7 -day incubation period at $30^{\circ} \mathrm{C}$ on $\mathrm{R} 2 \mathrm{~A}$ agar.

Analysis of fatty acid methyl esters was performed according to the instructions of the Microbial Identification System (MIDI; Microbial ID, Inc.). Analyses of polar lipids and isoprenoid quinones were carried out using the methods described by Komagata \& Suzuki (1987). The DNA G + C content of strain EMB $111^{\mathrm{T}}$ was determined using an HPLC system fitted with a reversed-phase column (GROM-SIL 100 ODS-2FE; GROM) according to the method of Tamaoka \& Komagata (1984). The major respiratory lipoquinone of strain EMB111 ${ }^{\mathrm{T}}$ was menaquinone-7 (MK-7). The cellular fatty acids of the isolate included iso- $\mathrm{C}_{15: 0}(29 \cdot 5 \%)$, summed feature $3\left(\mathrm{C}_{16: 1} \omega 7 \mathrm{c}\right.$ and/or iso- $\mathrm{C}_{15: 0} 2-\mathrm{OH}$; $19 \cdot 5 \%), \mathrm{C}_{16: 1} \omega 5 c(12 \cdot 9 \%)$, iso- $\mathrm{C}_{17: 0} 3-\mathrm{OH}(9 \cdot 2 \%)$, iso$\mathrm{C}_{15: 0} 3-\mathrm{OH}(6 \cdot 7 \%), \mathrm{C}_{16: 0} 3-\mathrm{OH}(5 \cdot 7 \%), \mathrm{C}_{16: 0}(5 \cdot 5 \%)$, $\mathrm{C}_{15: 0}(2 \cdot 5 \%)$, iso- $\mathrm{C}_{15: 1} \mathrm{G}(2 \cdot 4 \%)$, iso- $\mathrm{C}_{13: 0}(1 \cdot 8 \%)$, anteiso- $\mathrm{C}_{15: 0}(1 \cdot 7 \%)$, iso- $\mathrm{C}_{16: 0} 3-\mathrm{OH}(0 \cdot 8 \%)$, iso- $\mathrm{C}_{16: 0}$
$(0 \cdot 8 \%), \mathrm{C}_{14: 0}(0 \cdot 8 \%)$, iso- $\mathrm{C}_{17: 0}(0 \cdot 3 \%)$ and iso- $\mathrm{C}_{14: 0}$ $(0 \cdot 2 \%)$. The strain contained a large amount of phosphatidylglycerol (PG) and small amounts of two unknown phospholipids (PL1, PL2). The G $+\mathrm{C}$ content of the genomic DNA of strain EMB $111^{\mathrm{T}}$ was $42.7 \mathrm{~mol} \%$. The phenotypic characteristics of strain $\mathrm{EMB} 111^{\mathrm{T}}$ are summarized and compared with those of the type strains of closely related taxa in Table 1.

Sequencing and assembling of the 16S rRNA gene were carried out as described by DeLong (1992). The resultant $16 \mathrm{~S}$ rRNA gene sequence of strain EMB $111^{\mathrm{T}}$ was compared with available sequences from GenBank using the BLAST program (http://www.ncbi.nlm.nih.gov/blast/) to determine an approximate phylogenetic affiliation, and the gene sequence was aligned with those of closely related strains using CLUSTAL W software (Thompson et al., 1994). Phylogenetic trees were constructed using three different methods, the neighbour-joining, maximum-likelihood and maximum-parsimony algorithms, which are available in the PHYLIP software, version 3.6 (Felsenstein, 2002). Sequence similarity values were computed by using Similarity Matrix version 1.1 (Ribosomal Database Project II; http:// 35.8.164.52/html/; Cole et al., 2003). A bootstrap analysis was performed according to the algorithm of the Kimura two-parameter model (Kimura, 1980) of the neighbourjoining method using the PHYLIP package. Phylogenetic analysis using a nearly complete $16 \mathrm{~S}$ rRNA gene sequence $(1428 \mathrm{nt})$ of strain $\mathrm{EMB} 111^{\mathrm{T}}$ indicated that the isolate formed a phyletic cluster with members of the genus Runella with $100 \%$ bootstrap support (Fig. 1). The strain was most closely related to R. slithyformis ATCC $29530^{\mathrm{T}}$ with a $16 \mathrm{~S}$ rRNA gene sequence similarity of $94 \cdot 8 \%$. The topologies of phylogenetic trees built using the maximum-likelihood and maximum-parsimony algorithms also supported the notion that the isolate belongs to the genus Runella (data not

Table 1. Differential characteristics of strain EMB $111^{\top}$ and type strains of selected related species

Strains: 1, strain EMB111 ${ }^{\mathrm{T}}$; 2, R. slithyformis ATCC $29530^{\mathrm{T}}$ (data from Chelius \& Triplett, 2000); 3, R. zeae NS12 ${ }^{\mathrm{T}}$ (Chelius et al., 2002); 4 ,

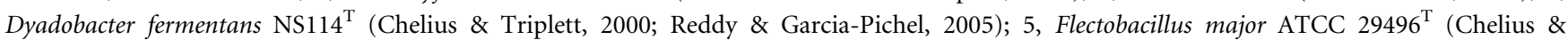
Triplett, 2000). Symbols: + , positive; - , negative; $(+)$, slightly positive; NA, no data available.

\begin{tabular}{|c|c|c|c|c|c|}
\hline Characteristic & 1 & 2 & 3 & 4 & 5 \\
\hline Colony colour & Salmon pink & Salmon pink & Salmon pink & Yellow & Pink \\
\hline Oxidase & - & + & + & + & + \\
\hline Catalase & + & $(+)$ & + & + & $(+)$ \\
\hline Gelatin hydrolysis & - & - & - & - & $(+)$ \\
\hline Major cellular fatty acids & $\begin{array}{l}\text { iso- } C_{15: 0}, C_{16: 1} \omega 5 c \text {, } \\
\text { summed feature } 3^{*}\end{array}$ & NA & $\begin{array}{l}\mathrm{C}_{16: 1} \omega 5 c, \text { iso- } \mathrm{C}_{15: 0} \\
\text { summed feature } 3^{*}\end{array}$ & $\begin{array}{c}\text { iso- } \mathrm{C}_{15: 0}, \\
\mathrm{C}_{16: 1} \omega 5 c, \mathrm{C}_{16: 1} \omega 7 c\end{array}$ & NA \\
\hline DNA $G+C$ content $(\mathrm{mol} \%)$ & $42 \cdot 7$ & 49 & 49 & 48 & 40 \\
\hline
\end{tabular}

${ }^{*}$ Summed feature 3 comprises $\mathrm{C}_{16: 1} \omega 7 c$ and/or iso- $\mathrm{C}_{15: 0}$ 2-OH. 


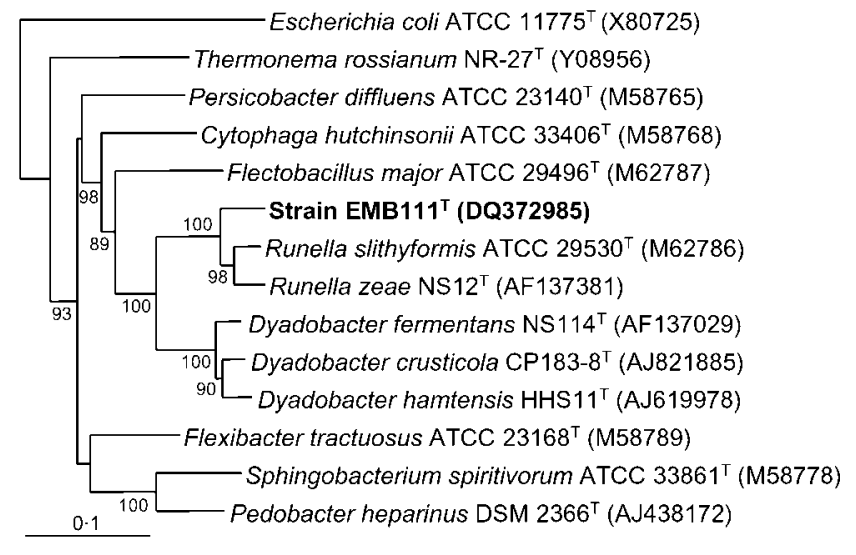

Fig. 1. Neighbour-joining tree based on 16S rRNA gene sequences showing the phylogenetic relationships of strain EMB $111^{\top}$ and related taxa. Bootstrap values are shown as percentages of 1000 replicates; only values $>50 \%$ are shown. Escherichia coli ATCC $11775^{\top}$ was used as an outgroup. Bar, $0 \cdot 1$ changes per nucleotide position.

shown). Therefore, the physiological, biochemical and phylogenetic properties of strain EMB $111^{\mathrm{T}}$ suggest that it represents a novel species of the genus Runella within the family Flexibacteraceae, for which the name Runella limosa sp. nov. is proposed.

\section{Description of Runella limosa sp. nov.}

Runella limosa (li.mo'sa. L. fem. adj. limosa muddy, pertaining to sludge, the natural habitat of the species).

Colonies are slightly raised, circular and salmon-pink in colour on R2A agar. Growth occurs optimally at $25-30{ }^{\circ} \mathrm{C}$ and $\mathrm{pH} 7 \cdot 5-8 \cdot 0$. Cells are Gram-negative, non-motile, long rods, $0 \cdot 7-0 \cdot 9 \mu \mathrm{m}$ wide and $4 \cdot 0-10 \cdot 0 \mu \mathrm{m}$ long when grown at $25^{\circ} \mathrm{C}$ on R2A agar. Nitrate is not reduced to nitrite. Catalase-positive and oxidase-negative. Tyrosine, Tween 80 and aesculin are hydrolysed. Casein, Tween 20, starch, gelatin and urea are not hydrolysed. Acids are produced from D-glucose, D-raffinose, myo-inositol, D-lactose, D-mannitol and melibiose, but not from sorbitol, sucrose, rhamnose, amygdalin, D-fructose, D-galactose, D-mannose, L-arabinose, arbutin or salicin. Produces alkaline phosphatase, $\alpha$-chymotrypsin, $N$-acetyl- $\beta$-glucosaminidase and naphthol-AS-BI-phosphohydrolase, but not esterase (C4), esterase lipase (C8), lipase (C14) or cystine arylamidase. Weak enzymic activities are observed for leucine arylamidase, valine arylamidase, trypsin, $\beta$-galactosidase, $\alpha$-glucosidase, $\beta$-glucosidase, acid phosphatase, $\alpha$-galactosidase, $\beta$-glucuronidase, $\alpha$-mannosidase and $\alpha$-fucosidase. The strain contains a large amount of phosphatidylglycerol and small amounts of two unknown phospholipids (PL1, PL2). The major isoprenoid quinone is MK-7. The major fatty acids are iso- $\mathrm{C}_{15: 0}, \mathrm{C}_{16: 1} \omega 5 c$, iso- $\mathrm{C}_{17: 0} 3-\mathrm{OH}$, iso$\mathrm{C}_{15: 0} 3-\mathrm{OH}, \mathrm{C}_{16: 0} 3-\mathrm{OH}, \mathrm{C}_{16: 0}$ and summed feature 3
$\left(\mathrm{C}_{16: 1} \omega 7 c\right.$ and/or iso- $\left.\mathrm{C}_{15: 0} 2-\mathrm{OH}\right)$. The DNA G $+\mathrm{C}$ content is $42 \cdot 7 \mathrm{~mol} \%$ (HPLC).

The type strain, EMB111 ${ }^{\mathrm{T}} \quad\left(=\mathrm{KCTC} \quad 12615^{\mathrm{T}}=\mathrm{DSM}\right.$ $\left.17973^{\mathrm{T}}\right)$, was isolated from sludge performing enhanced biological phosphorus removal.

\section{Acknowledgements}

This study was supported by grants from the MOST/KOSEF to the Environmental Biotechnology National Core Research Center (grant no. R15-2003-012-02002-0) and to the 21C Frontier Microbial Genomics and Application Center Program (grant no. MG05-01044-0), Ministry of Science \& Technology, Korea. S. H. R. and T. T. H. N. were supported by scholarships from the BK21 program, the Ministry of Education and Human Resources Development in Korea.

\section{References}

Chelius, M. K. \& Triplett, E. W. (2000). Dyadobacter fermentans gen. nov., sp. nov., a novel Gram-negative bacterium isolated from surface-sterilized Zea mays stems. Int J Syst Evol Microbiol 50, 751-758.

Chelius, M. K., Henn, J. A. \& Triplett, E. W. (2002). Runella zeae sp. nov., a novel Gram-negative bacterium from the stems of surfacesterilized Zea mays. Int J Syst Evol Microbiol 52, 2061-2063.

Cole, J. R., Chai, B., Marsh, T. L. \& 8 other authors (2003). The ribosomal database project (RDP-II): previewing a new autoaligner that allows regular updates and the new prokaryotic taxonomy. Nucleic Acids Res 31, 442-443.

DeLong, E. F. (1992). Archaea in coastal marine environments. Proc Natl Acad Sci U S A 89, 5685-5689.

Felsenstein, J. (2002). PHYLIP - Phylogeny Inference Package, version 3.6a. Distributed by the author. Department of Genome Sciences, University of Washington, Seattle, USA.

Gerhardt, P., Murray, R. G. M., Wood, W. A. \& Krieg, N. R. (1994). Phenotypic characterization. In Methods for General and Molecular Bacteriology, pp. 607-654. Edited by P. Gerhardt. Washington, DC: American Society for Microbiology.

Gomori, G. (1955). Preparation of buffers for use in enzyme studies. Methods Enzymol 1, 138-146.

Jeon, C. O., Lee, D. S. \& Park, J. M. (2003). Microbial communities in activated sludge performing enhanced biological phosphorus removal in a sequencing batch reactor. Water Res 37, 2195-2205.

Jeon, C. O., Lim, J. M., Lee, J. M., Xu, L. H., Jiang, C. L. \& Kim, C. J. (2005). Reclassification of Bacillus haloalkaliphilus Fritze 1996 as Alkalibacillus haloalkaliphilus gen. nov., comb. nov. and the description of Alkalibacillus salilacus sp. nov., a novel halophilic bacterium isolated from a salt lake in China. Int J Syst Evol Microbiol 55, 743-746.

Kimura, M. (1980). A simple method for estimating evolutionary rates of base substitutions through comparative studies of nucleotide sequences. J Mol Evol 16, 111-120.

Komagata, K. \& Suzuki, K. (1987). Lipid and cell-wall analysis in bacterial systematics. Methods Microbiol 19, 161-208.

Lanyi, B. (1987). Classical and rapid identification methods for medically important bacteria. Methods Microbiol 19, 1-67.

Larkin, J. M. \& Williams, P. M. (1978). Runella slithyformis gen. nov., sp. nov., curved nonflexible, pink bacterium. Int J Syst Bacteriol 28, 32-36. 
Leifson, E. (1963). Determination of carbohydrate metabolism of marine bacteria. J Bacteriol 85, 1183-1184.

Reddy, G. S. N. \& Garcia-Pichel, F. (2005). Dyadobacter crusticola sp. nov., from biological soil crusts in the Colorado Plateau, USA, and an emended description of the genus Dyadobacter Chelius and Triplett 2000. Int J Syst Evol Microbiol 55, 1295-1299.
Tamaoka, J. \& Komagata, K. (1984). Determination of DNA base composition by reverse-phase high-performance liquid chromatography. FEMS Microbiol Lett 25, 125-128.

Thompson, J. D., Higgins, D. G. \& Gibson, T. J. (1994). CLUSTAL W: improving the sensitivity of progressive multiple sequence alignment through sequence weighting, position-specific gap penalties and weight matrix choice. Nucleic Acids Res 22, 4673-4680. 